\title{
Comparative study between trabeculectomy with photodynamic therapy (BCECF-AM) and trabeculectomy with antimetabolite (MMC) in the treatment of primary open angle glaucoma
}

\author{
This article was published in the following Dove Press journal: \\ Clinical Ophthalmology \\ 9 October 2012 \\ Number of times this article has been viewed
}

\author{
Ahmed M Saeed \\ Ophthalmology Department, Benha \\ University, Benha, Egypt
}

Background: Various methods have been investigated to avoid postoperative scarring of the filtering bleb in modern glaucoma surgery. Most deal with the application of antimetabolic drugs such as mitomycin C (MMC). 2',7'-bis-(2-carboxyethyl)-5-(and-6)-carboxyfluorescein, acetoxymethyl ester (BCECF-AM) is a locally acting intracellular photosensitizer which could control and decrease postoperative fibrosis at the trabeculectomy site.

Purpose: To compare the effect of photodynamic therapy in combination with trabeculectomy to the effect of MMC combined with the same procedure in controlling postoperative intraocular pressure (IOP) in patients with medically uncontrolled primary open angle glaucoma (1ry OAG).

Methods: A randomized controlled clinical trial was conducted on 76 eyes of 76 patients divided into three groups undergoing trabeculectomy, trabeculectomy with BCECF-AM (group A), trabeculectomy with MMC (group B), and trabeculectomy only as a control group (group C). Patients were reviewed postoperatively for clinical evaluation and photo documentation of the blebs with a fundus camera and ultrasonic biomicroscopy (UBM). The desirable effect of the adjunctive material was evaluated according to the clinical efficacy, tolerability, and safety by comparison with the control group.

Setting: Benha University Hospital, Benha, Egypt.

Results: After a mean follow-up of 24 months, all procedures succeeded in lowering IOP. The cumulative probability of complete success at the 24 month follow-up was $91 \%$ for group B, compared to $82 \%$ and $81.5 \%$ for group A and group C, respectively. The percentage of complete success was highest for group B, second highest for group A, and lowest for group $\mathrm{C}$ over the follow-up period; however, these differences were not statistically significant $(P>0.05)$. Regarding the bleb morphology and UBM reflectivity, the differences were not statistically significant $(P>0.05)$. The mean bleb height and breadth were larger in groups $\mathrm{A}$ and $\mathrm{B}$ in comparison to group $\mathrm{C}$ over the study period. The mean aqueous drainage route was similar in groups $\mathrm{A}$ and $\mathrm{C}$, but less than in group B at 3 and 12 months postoperatively. Complications were generally mild and less marked in group A and $\mathrm{C}$ than group B.

Conclusion: Cellular photoablation using BCECF-AM seems to be a feasible new method to use in combination with glaucoma filtration surgery. Although MMC might be considered a more potent adjunctive to trabeculectomy in promoting IOP reduction, photodynamic therapy carries relatively less risk of adverse effects and complications. Cellular photoablation using BCECF-AM could be considered efficient, tolerable and relatively safer in managing patients with 1ry OAG. Further studies are necessary to determine the safety and the reliability of this therapy.

Keywords: photodynamic therapy, mitomycin C, trabeculectomy, open angle glaucoma, ultrasonic biomicroscopy
Correspondence: Ahmed M Saeed Ophthalmology Department, Benha University, Zayed Tower, El-souq Eltougary St, El-Qanatir El-Khairiya, |362|, Al-Qalyubiyah, Egypt

Tel +20 I 227468426

Fax +20242197773

E-mail a_saeed775@yahoo.com submit your manuscript $\mid$ www.dovepress.com

Dovepress

http://dx.doi.org// 0.2147/OPTH.S29909 which permits unrestricted noncommercial use, provided the original work is properly cited. 


\section{Introduction}

Trabeculectomy is the most frequently applied surgical method to reduce intraocular pressure (IOP) in patients with glaucoma. Various methods have been investigated in order to avoid naturally occurring scarring of the filtering bleb and subsequent to lower the incidence of this detrimental complication. Antimetabolic drugs, 5 -fluorouracil (5-FU) or mitomycin C (MMC), are the two most widely used cytotoxic agents for intraoperative or postoperative application. ${ }^{1,2}$ Despite the positive effect MMC has on filtering surgery success rates, its diffusion into adjacent ocular tissues may lead to toxic effects on cells not targeted during treatment. ${ }^{3-5}$

Photodynamic therapy might be an alternative way to solve this problem. ${ }^{6}$ Photosensitizers can be used as mediators of light-induced cell toxicity. They seem to act via the formation of reactive oxygen intermediates and free radicals. ${ }^{7-10}$ Several photosensitizers are currently under investigation in ophthalmology. Cellular photoablation can be mediated by 2',7'-bis-(2-carboxyethyl)-5-(and-6)-carboxyfluorescein, acetoxymethyl ester (BCECF-AM). ${ }^{11-15}$

BCECF-AM is a cell membrane permeable compound rendered membrane impermeable and fluorescent upon cleavage by intracellular esterase. Exposure of cells that have incorporated BCECF-AM to blue light leads to a photo oxidative effect that is only cell destructive within the targeted cells. ${ }^{7-10}$ Furthermore, this effect is strictly limited to the local restriction of the illuminated area. ${ }^{16}$

\section{Aim}

The aim of this trial is to compare the effect of photodynamic therapy with BCECF-AM in combination with trabeculectomy to the effect of MMC combined with the same procedure in controlling postoperative IOP in patients with uncontrolled primary open angle glaucoma (1ry OAG). The desirable effect of the adjunctive material is evaluated according to the clinical efficacy, tolerability, and safety in comparison to a control group, guided by bleb photos and ultrasonic biomicroscopy (UBM) imaging.

\section{Subjects and methods}

This randomized comparative clinical trial was conducted upon 76 eyes of 76 patients ( 36 males and 40 females) presented with 1ry OAG. All eyes had uncontrolled IOP despite maximum tolerable antiglaucoma therapy. Patients were selected from those attending ophthalmology clinics at Benha University Hospital. There was no statistically significant variation between the groups studied regarding their race, gender $(P=0.62)$, and age $(P=0.9)$. The mean age was $58.6 \pm 8.4,58.8 \pm 8.8$, and $59.0 \pm 9.2$ in groups $A$, $\mathrm{B}$, and $\mathrm{C}$, respectively.

Exclusion criteria included patients with all types of glaucoma other than primary OAG; patients with any other ocular diseases; patients with a single functional eye; patients with previous intraocular surgery; patients refusing to receive the drugs after thorough explanation of their nature, possible adverses effects and complications (in groups A and B), and patients who were not willing to give consent; and patients who missed two subsequent follow-up visits.

Baseline data included the following:

- Reference IOP was measured using the Goldmann applanation tonometer. It was defined as the mean of at least three IOP readings at different hours of the day on at least 2 days, not necessarily consecutive, within 1 month before the surgery even if the patient was on a full medical regimen.

- Central corneal thickness was measured using an ultrasonic pachymeter (Corneo-Gage Plus ${ }^{\mathrm{TM}} 4 \mathrm{~s}$; Sonogage, Inc, Cleveland, $\mathrm{OH}$ ).

- Ocular hypotensive medications were used and their class, number, duration, and evidence of chronic inflammation were recorded.

- At least two field examinations were conducted before the surgery using a Humphrey FTD ${ }^{\circledR}$ Perimeter (Carl Zeiss Meditec, Inc, Dublin, CA) to obtain the mean deviation.

- Best corrected visual acuity (BCVA) was determined using standard Snellen charts.

- The following examinations were also carried out: a complete ocular examination; a slit-lamp examination of the anterior segment, a gonioscopy using a Goldman contact lens, a fundus examination. A history of systemic diseases (diabetes mellitus, hypertension, collagen diseases, hepatitis, etc) was also recorded.

\section{The study design}

In this randomized comparative clinical trial, only one eye of each patient was included in the study. Five patients were excluded from the study because they missed two subsequent postoperative follow-up visits. The eyes were divided into three groups: trabeculectomy with BCECF-AM (group A $=25$ eyes), using simple randomization method trabeculectomy with $\mathrm{MMC}$ (group B $=24$ eyes), and trabeculectomy only as a control group (group $\mathrm{C}=22$ eyes). The surgical procedure was performed under local anesthesia by the same surgeon (Saeed) for all patients during the period from August 2009 to July 2010. 
In group A, the samples of the photosensitizer applied, BCECF-AM ester, $1 \mathrm{mg} / \mathrm{mL}$ indimethyl sulfoxide were provided by (Sigma-Aldrich ${ }^{\circledR}$, St Louis, MO). A dose of $80 \mu \mathrm{g}$ BCECF-AM was diluted in $300 \mu \mathrm{L}$ balanced salt solution (BSS) and stored at $-20^{\circ} \mathrm{C}$. A single dose of BCECF-AM ( $80 \mu \mathrm{g}$ in $300 \mu \mathrm{L}$ BSS) was applied by subconjunctival injection in the region of the proposed filtering bleb in the operative room. The injection was made $10 \mathrm{~mm}$ from the corneal limbus by a 27 gauge needle, a fornix-based conjunctival flap was performed, and the episcleral and subconjunctival Tenon were irradiated for 8 minutes, starting 15 minutes after the injection, with blue light provided by direct ophthalmoscope (Welch Allyn ${ }^{\circledR}$, Skaneateles, NY) from a distance of approximately $2 \mathrm{~cm}$. To minimize light dispersion, the cone of light was focused to approximately $15 \mathrm{~mm}$ in diameter, and the cornea was covered by tape.

In all groups, a fornix-based conjunctival flap was prepared for each case. A nearly half-thickness scleral flap, $3.5 \mathrm{~mm} \times 3.5 \mathrm{~mm}$, was dissected into clear cornea.

In group $\mathrm{B}$, a cellulose microsponge soaked in $0.4 \mathrm{mg} / \mathrm{mL}$ MMC (Mitomycin-C Kyowa ${ }^{\circledR}$; Kyowa Hakko Kogyo Co, Ltd, Tokyo, Japan) solution was applied to either surface of the scleral flap, with the conjunctive draped over the sponge for 3 minutes. The sponge was then removed and the entire area was lightly and copiously washed with irrigating saline.

In all groups, a standard trabeculectomy of equal size $(1 \mathrm{~mm} \times 1 \mathrm{~mm})$ was created using a Kelly punch, a peripheral iridectomy was made using scissors, the scleral flap was closed with two 10-0 nylon sutures, and the conjunctiva was closed with 8-0 (Vicryl ${ }^{\circledR}$ polyglactin 910 ; Ethicon Inc, Johnson \& Johnson, Somerville, NJ) sutures.

The same technique was used in group $\mathrm{C}$ patients but without injecting BCECF-AM or applying MMC.

Any intraoperative complication was recorded. After surgery, prednisolone acetate $1 \%$ and gatifloxacin $0.3 \%$ (Optipred $^{\circledR}$ and Tymer ${ }^{\circledR} ;$ Jamjoom Pharma, Jeddah, Saudi Arabia) eye drops were administered five times daily for 2 weeks. Cyclopentolate 1.0\% (Cycloplejico ${ }^{\circledR}$ eye drop; Alcon Cusi, SA, El Masnou, Barcelona, Spain) was given three times daily for 1 week. No topical or systemic antiglaucoma medication was given.

Postoperative examinations were performed 2 days; 1 and 2 weeks; and 1, 3, 6, 12, 18, and 24 months after the surgery for BCVA, examination of the anterior segment, morphology of the filtering bleb, IOP and any antiglaucoma drugs needed to control it, examination of the fundus, and photo documentation of the anterior segment and the filtering bleb with colored photography using a Humphrey FTD $^{\circledR}$ Perimeter (Carl Zeiss Meditec, Inc, Dublin, CA). fundus camera (model 1203-77; Carl Zeiss Meditec, Inc), and ultrasound biomicroscopy (UBM) (model Dicon P45 UBM plus; Paradigm Usa Inc, Lodi, NJ). Patients' symptoms, any postoperative complications, and any side effects caused by the materials used were observed and recorded.

"Efficacy" was defined as postoperative IOP reduction. "Complete success" was defined as an IOP reduction of $>20 \%$ and/or an IOP constantly $<21 \mathrm{mmHg}$ without any antiglaucoma medication. "Qualified success" was defined as an IOP $<21 \mathrm{mmHg}$ with topical antiglaucoma medication. "Failure" was defined when IOP $>21 \mathrm{mmHg}$ in 2 subsequent follow-up visits despite topical antiglaucoma therapy. "Complete failure" was used to describe situations where there was a need for further glaucoma surgical interventions or when patients had no perception of light attributable to glaucoma progression. ${ }^{17}$

Colored photography of the filtering blebs was performed. They were classified according to their morphology into the following types. ${ }^{18} \mathrm{~A}$ type I bleb is a thin-walled, polycystic bleb with a transconjunctival flow of fluid and thus well functioning. A type II bleb is described as flatter, thicker, more diffuse and perilimbally extended, relatively avascular, and with good function. A type III bleb is a flattened bleb with little or no function in which the scarred conjunctiva firmly adheres to the underlying sclera. A type IV bleb is an encapsulated bleb (Tenon's capsule cyst) with some engorged surface blood vessels. ${ }^{19}$

UBM examination was conducted about 3,12 , and 24 months postoperatively to evaluate the reflectivity inside the filtering bleb (low, medium, and high), to measure their dimensions (height and breadth), and to realize visibility of the aqueous drainage route (visible and measure it or none or poorly visible)..$^{20,21}$

A visual field examination was carried out on all patients in the study groups preoperatively and at 12, and 24 months postoperatively. The baseline mean deviation and pattern standard deviation (PSD) values were considered for two preoperative field examinations-within 1 month-using a threshold 24-2 test with size III stimulus using Humphrey automated perimetry.

\section{Statistical analysis}

The collected data were tabulated and analyzed using SPSS ${ }^{\circledR}$ version 16 software (IBM ${ }^{\circledR}$ Corporation, Armonk, NY). A survival curve and a log rank test were used to assess and compare the probability of success among the groups 
studied. Categorical data were presented as numbers and percentages, and $\chi^{2}$ tests and Spearman's rank correlation coefficient ( $r$ ) were used as tests of significance, while continuous variables were expressed as mean and standard deviations, with an analysis of variance and paired $t$-test as tests of significance. The accepted level of significance in this work was stated at $0.05(P<0.05$ was considered significant).

\section{Results}

The outcome data for all patients were summarized and represented according to the above mentioned definitions of success. The mean and SD values of the IOP in the three groups all over the study period were represented in Figure 1 and Table 1. The survival curve (Figure 2) demonstrates the surgical success, and the tables show the numbers in each study group analyzed at each postoperative follow-up time point of 6, 12, 18, 24 months postoperatively (Tables 2-5, respectively). Scatter plots illustrate the proportions of study subjects who meet the criteria for success at 12,18 , and 24 months postoperatively (Figures 3-5 respectively). The diagonal lines in Figures 3-5 differentiate those with an IOP reduction after surgery (right lower half) from those with an IOP increase after surgery (left upper half). Those with no change fall on the diagonal line. Pearson's correlation coefficient between baseline IOP and postoperative IOP at 12, 18, 24 months were also represented (Table 6).
The percentage of complete success was highest for group B, second highest for group A, and lowest for group C over the follow-up period. The percentage of failure and complete failure was least in group B over the follow-up period, and then group $\mathrm{A}$, and highest for group $\mathrm{C}$ during the 12 months; however, it became nearly equal for groups $\mathrm{A}$ and $\mathrm{C}$ near the end of the study period. These differences were not statistically significant $(P>0.05)$ (Tables $2-5)$.

There were four, two, and four cases of complete failure in groups A, B, and C respectively. All were due to excessive scarring. The patients needed a second intervention procedure by either revision of the original fistula with MMC application (eight eyes) or by creating another fistula at a different site (two eyes, one in group A and one in group C). All cases reported complete success thereafter (Tables 2-5).

Table 7 and Figure 6 show the number of the patients in each group receiving topical antiglaucoma drugs at 24 months postoperatively.

At the 24-month follow-up visit, the highest percentage of patients requiring antiglaucoma treatment was in group $\mathrm{C}$. The percentage was much lower and nearly equal in groups $\mathrm{A}$ and $\mathrm{B}$, but this difference was not statistically significant $(P=0.22)$. Only three patients, all in group $\mathrm{C}$, needed three drugs to keep their IOP controlled (Table 7).

The highest percentage of group B $(66.7 \%)$ showed low reflectivity compared to $40 \%$ of group A and only $15 \%$ of group $\mathrm{C}$, but this difference was not statistically significant $(\mathrm{P}>0.05)($ Table 8$)$.

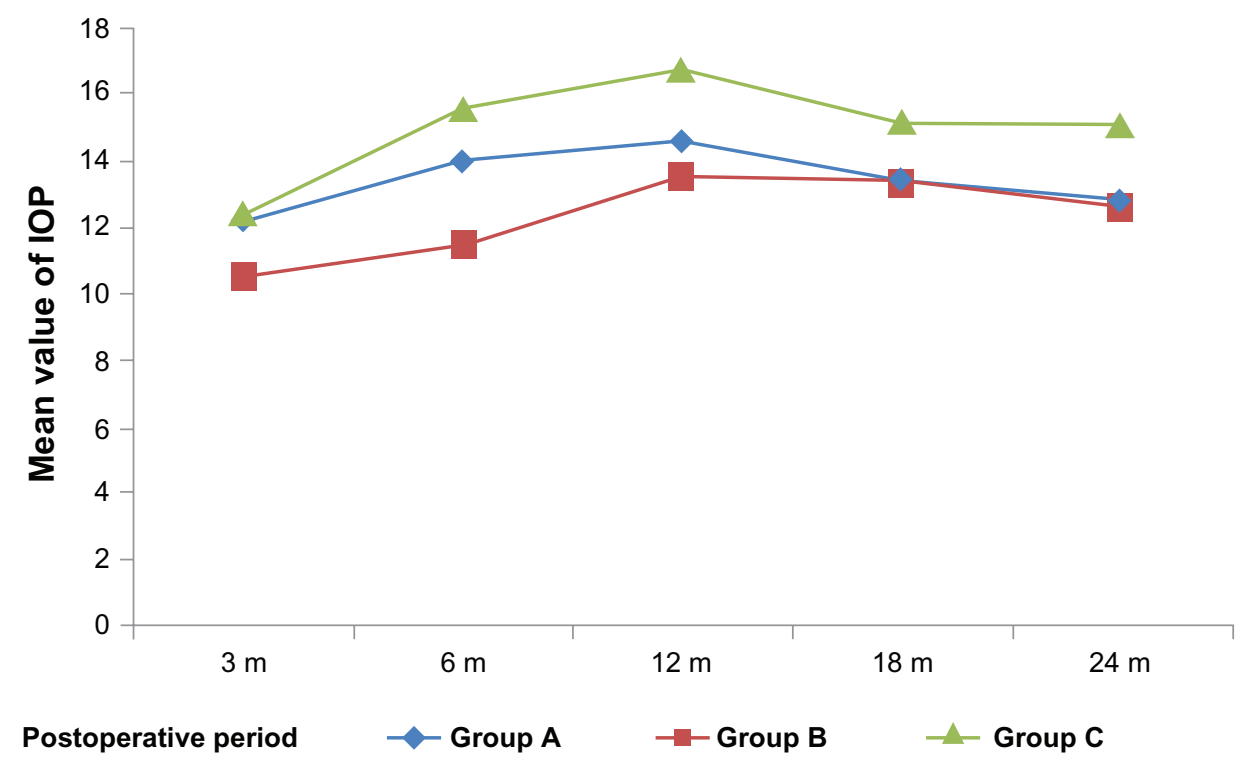

Figure I The mean and standard deviation (SD) values of the intraocular pressure (IOP) in the three groups throughout the study period.

Notes: The mean and SD of the postoperative IOP values were always less in Groups A and B than in the controls and showed a statistically significant difference only at 6 months postoperatively. The cumulative probability of complete success at 24 months follow-up is 0.91 for group B, compared to 0.82 and 0.815 for group A and group C, respectively; however, this difference was statistically nonsignificant $(P>0.05)$. 
Table I The mean and standard deviation (SD) values of the intraocular pressure (IOP) in the three groups throughout the study period

\begin{tabular}{|c|c|c|c|c|c|c|c|c|}
\hline \multirow[t]{2}{*}{ Variable } & \multicolumn{2}{|c|}{ Group A } & \multicolumn{2}{|c|}{ Group B } & \multicolumn{2}{|c|}{ Group C } & \multirow[t]{2}{*}{ ANOVA } & \multirow[t]{2}{*}{$P$} \\
\hline & Mean & $\pm \mathrm{SD}$ & Mean & $\pm \mathrm{SD}$ & Mean & $\pm \mathrm{SD}$ & & \\
\hline IOP $3 \mathrm{~m}$ & 12.2 & 2.1 & 10.50 & 2.4 & $12.4 \mid$ & 2.3 & 4.99 & 0.009 \\
\hline IOP $6 \mathrm{~m}$ & 13.96 & 3.5 & 11.45 & 2.3 & 15.54 & 4.2 & 8.5 & 0.001 \\
\hline IOP I2 m & 14.60 & 4.2 & 13.50 & 3.8 & 16.73 & 4.6 & 3.45 & 0.037 \\
\hline IOP 18 m & 13.40 & 4.1 & 13.37 & 4.4 & 15.14 & 4.4 & 1.28 & 0.285 \\
\hline IOP 24 m & 12.84 & 1.2 & 12.58 & 1.3 & 15.09 & 4.4 & 6.02 & 0.004 \\
\hline
\end{tabular}

Group B showed the highest percentage of type I blebs (45.8\%), group A showed highest percentage of type II blebs (36\%), and group $\mathrm{C}$ showed the highest percentage of types III and IV blebs (32\% and $23 \%$ of the patients, respectively). The difference was not statistically significant $(P>0.05)$ (Table 8).

The mean bleb height was markedly larger in groups $\mathrm{A}$ and $\mathrm{B}$ in comparison to group $\mathrm{C}$ over the study period. This difference was statistically significant at 24 months postoperatively when only comparing group B with the controls $(P<0.05)$ (Table 9).

The mean bleb breadth was larger in groups A and B in comparison to group $\mathrm{C}$ over the follow-up period. The differences were always statistically significant. The mean bleb breadth was always larger in group B than group A; however, the difference was only statistically significant at 3 and 12 months (Table 9).

The mean aqueous drainage route was nearly equal in groups $\mathrm{A}$ and $\mathrm{C}$, but it was less than in group $\mathrm{B}$ at 3 and 12 months postoperatively. At 24 months and after, excluding all poorly visible cases ( six cases in group A, five cases in group B, and seven cases in group C), group A showed the highest mean drainage routes. All differences were not statistically significant (Table 9).

There were no statistically significant differences in the mean PSD from the Humphrey automated perimetry between the three groups preoperatively or 12 and 24 months postoperatively $(P>0.05)$. In groups $\mathrm{A}$ and $\mathrm{B}$, there were no statistically significant changes in the mean PSD at 12 or 24 months postoperatively compared to the

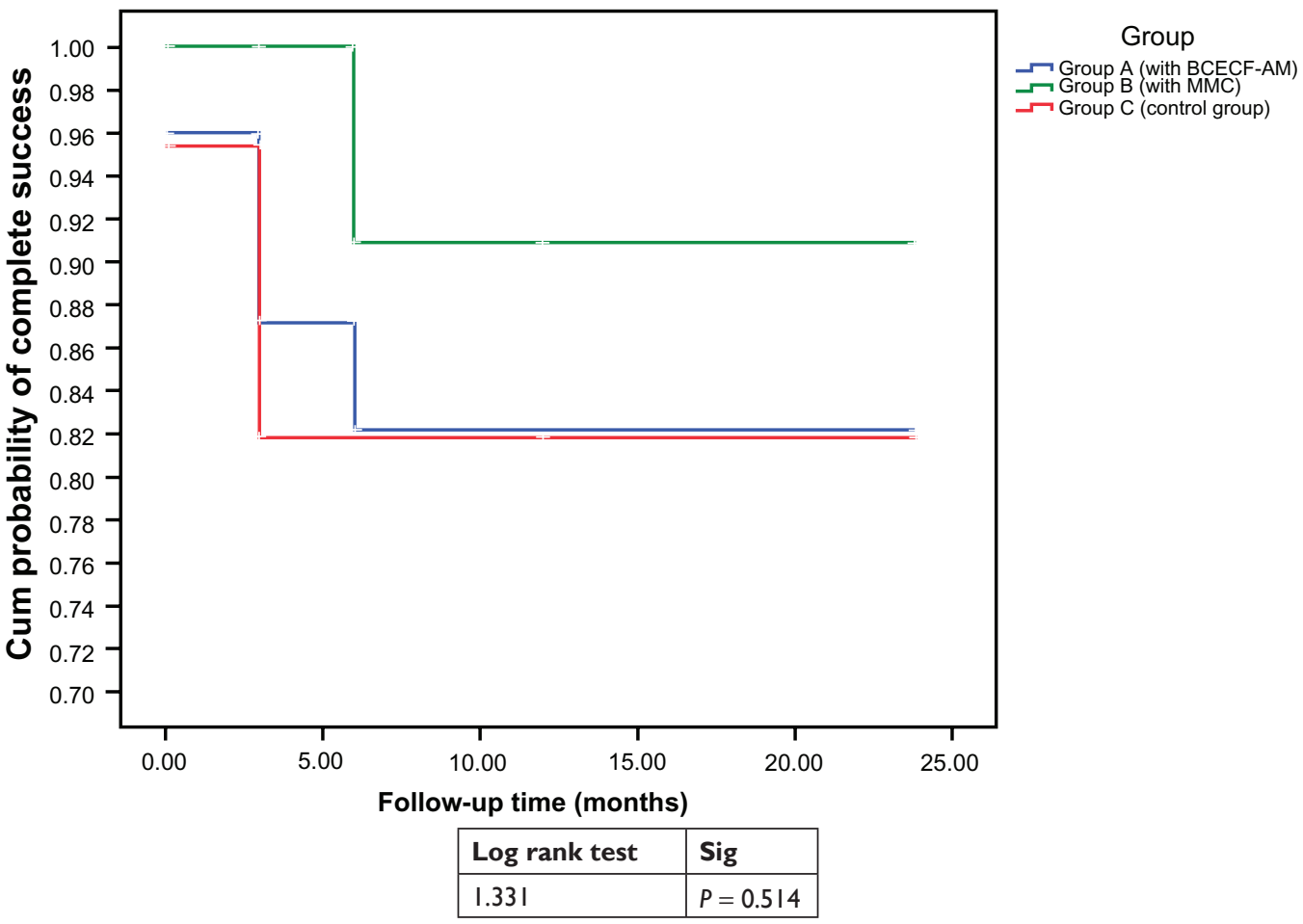

Figure 2 The survival curve that demonstrates the surgical success of the three groups all over the follow-up period of 24 months.

Note: Survival tables (Tables 2-5) respectively show the numbers in each study group analyzed at each follow up point at $6,12,18,24$ months postoperatively. Abbreviations: BCECF-AM, 2',7'-bis-(2-carboxyethyl)-5-(and-6)-carboxyfluorescein, acetoxymethyl ester; MMC, mitomycin C; Sig, significance. 
Table 2 Shows the numbers in each study group analyzed at 6 months postoperatively

\begin{tabular}{|c|c|c|c|c|c|c|}
\hline \multirow[t]{2}{*}{ Outcome $6 \mathrm{~m}$} & \multicolumn{6}{|l|}{ Group } \\
\hline & $\begin{array}{l}\text { Group A } \\
\text { (with BCFCF-AM) }\end{array}$ & $\begin{array}{l}\text { Group B } \\
\text { (with MMc) }\end{array}$ & $\begin{array}{l}\text { Group C } \\
\text { (control group) }\end{array}$ & Total & $\mathbf{X}^{2}$ & $\mathbf{P}$ \\
\hline \multicolumn{7}{|l|}{ Complete success } \\
\hline Count & $1 \%$ & 22 & 13 & 53 & 8.1 & 0.09 \\
\hline$\%$ within group & $72.0 \%$ & $91.7 \%$ & $59.1 \%$ & $74 . \%$ & & \\
\hline \multicolumn{7}{|l|}{ Qualified success } \\
\hline Count & 6 & 2 & 8 & 14 & & \\
\hline$\%$ within group & $24.0 \%$ & $0.3 \%$ & $27.3 \%$ & $19.7 \%$ & & \\
\hline \multicolumn{7}{|l|}{ Failure } \\
\hline Count & I & 0 & 3 & 4 & & \\
\hline$\%$ within group & $40 \%$ & $0 \%$ & $13.6 \%$ & $5.6 \%$ & & \\
\hline \multicolumn{7}{|l|}{ Total } \\
\hline Count & 2 & 24 & 22 & 71 & & \\
\hline$\%$ within group & $100.0 \%$ & $100.0 \%$ & $100.0 \%$ & $100.0 \%$ & & \\
\hline
\end{tabular}

Abbreviations: BCECF-AM, 2',7'-bis-(2-carboxyethyl)-5-(and-6)-carboxyfluorescein, acetoxymethyl ester; MMC, mitomycin C.

Table 3 Shows the numbers in each study group analyzed at 12 months postoperatively

\begin{tabular}{|c|c|c|c|c|c|c|}
\hline \multirow[t]{2}{*}{ Outcome $12 \mathrm{~m}$} & \multicolumn{3}{|l|}{ Group } & \multirow[t]{2}{*}{ Total } & \multirow[t]{2}{*}{$\mathbf{X}^{2}$} & \multirow[t]{2}{*}{$\mathbf{P}$} \\
\hline & $\begin{array}{l}\text { Group A } \\
\text { (with BCECF-AM) }\end{array}$ & $\begin{array}{l}\text { Group B } \\
\text { (with MMC) }\end{array}$ & $\begin{array}{l}\text { Group C } \\
\text { (control group) }\end{array}$ & & & \\
\hline \multicolumn{7}{|l|}{ Complete success } \\
\hline Count & 14 & 18 & 11 & 43 & 3.4 & 0.49 \\
\hline$\%$ within group & $56.0 \%$ & $75.0 \%$ & $50.0 \%$ & $60.6 \%$ & & \\
\hline \multicolumn{7}{|l|}{ Qualified success } \\
\hline Count & 8 & 4 & 8 & 20 & & \\
\hline$\%$ within group & $32.0 \%$ & $16.7 \%$ & $36.4 \%$ & $28.2 \%$ & & \\
\hline \multicolumn{7}{|l|}{ Failure } \\
\hline Count & 3 & 2 & 3 & 8 & & \\
\hline$\%$ within group & $12.0 \%$ & $8.3 \%$ & $13.6 \%$ & $11.3 \%$ & & \\
\hline \multicolumn{7}{|l|}{ Total } \\
\hline Count & 25 & 24 & 22 & 71 & & \\
\hline$\%$ within group & $100.0 \%$ & $100.0 \%$ & $100.0 \%$ & $100.0 \%$ & & \\
\hline
\end{tabular}

Abbreviations: BCECF-AM, 2',7'-bis-(2-carboxyethyl)-5-(and-6)-carboxyfluorescein, acetoxymethyl ester; MMC, mitomycin C.

Table 4 Shows the numbers in each study group analyzed at 18 months postoperatively

\begin{tabular}{|c|c|c|c|c|c|c|}
\hline \multirow[t]{2}{*}{ Outcome I 8} & \multicolumn{6}{|l|}{ Group } \\
\hline & $\begin{array}{l}\text { Group A } \\
\text { (with BCECF-AM) }\end{array}$ & $\begin{array}{l}\text { Group B } \\
\text { (with MMC) }\end{array}$ & $\begin{array}{l}\text { Group C } \\
\text { (control group) }\end{array}$ & Total & $\mathbf{X}^{2}$ & $\mathbf{P}$ \\
\hline \multicolumn{7}{|l|}{ Complete success } \\
\hline Count & 14 & 15 & 9 & 38 & 3.8 & 0.71 \\
\hline$\%$ within group & $56.0 \%$ & $62.5 \%$ & $40.9 \%$ & $53.5 \%$ & & \\
\hline \multicolumn{7}{|l|}{ Qualified success } \\
\hline Count & 6 & 7 & 8 & 21 & & \\
\hline$\%$ within group & $24.0 \%$ & $29.2 \%$ & $36.4 \%$ & $29.6 \%$ & & \\
\hline \multicolumn{7}{|l|}{ Failure } \\
\hline Count & 2 & 1 & 3 & 6 & & \\
\hline$\%$ within group & $8.0 \%$ & $4.2 \%$ & $13.6 \%$ & $8.5 \%$ & & \\
\hline \multicolumn{7}{|l|}{ Complete failure } \\
\hline Count & 3 & I & 2 & 6 & & \\
\hline$\%$ within group & $12.0 \%$ & $4.2 \%$ & $9.1 \%$ & $8.5 \%$ & & \\
\hline \multicolumn{7}{|l|}{ Total } \\
\hline Count & 25 & 24 & 22 & 71 & & \\
\hline$\%$ within group & $100.0 \%$ & $100.0 \%$ & $100.0 \%$ & $100.0 \%$ & & \\
\hline
\end{tabular}

Abbreviations: BCECF-AM, 2',7'-bis-(2-carboxyethyl)-5-(and-6)-carboxyfluorescein, acetoxymethyl ester; MMC, mitomycin C. 
Table 5 Shows the numbers in each study group analyzed at 24 months postoperatively

\begin{tabular}{|c|c|c|c|c|c|c|}
\hline \multirow[t]{2}{*}{ Outcome $12 \mathrm{~m}$} & \multicolumn{6}{|l|}{ Group } \\
\hline & $\begin{array}{l}\text { Group A } \\
\text { (with BCECF-AM) }\end{array}$ & $\begin{array}{l}\text { Group B } \\
\text { (with MMC) }\end{array}$ & $\begin{array}{l}\text { Group C } \\
\text { (control group) }\end{array}$ & Total & $\mathbf{X}^{2}$ & $\mathbf{P}$ \\
\hline \multicolumn{7}{|l|}{ Complete success } \\
\hline Count & 14 & 15 & 9 & 38 & 2.65 & 0.62 \\
\hline$\%$ within group & $56.0 \%$ & $62.5 \%$ & $40.9 \%$ & $53.5 \%$ & & \\
\hline \multicolumn{7}{|l|}{ Qualified success } \\
\hline Count & 7 & 7 & 9 & 23 & & \\
\hline$\%$ within group & $28.0 \%$ & $29.2 \%$ & $40.9 \%$ & $32.4 \%$ & & \\
\hline \multicolumn{7}{|l|}{ Complete failure } \\
\hline Count & 4 & 2 & 4 & 10 & & \\
\hline$\%$ within group & $16.0 \%$ & $8.3 \%$ & $18.2 \%$ & $14.1 \%$ & & \\
\hline \multicolumn{7}{|l|}{ Total } \\
\hline Count & 25 & 24 & 22 & 71 & & \\
\hline$\%$ within group & $100.0 \%$ & $100.0 \%$ & $100.0 \%$ & $100.0 \%$ & & \\
\hline
\end{tabular}

Abbreviations: BCECF-AM, 2',7'-bis-(2-carboxyethyl)-5-(and-6)-carboxyfluorescein, acetoxymethyl ester; MMC, mitomycin C.

preoperative status; however, the changes reached the level of significance in group C. Five eyes in group A (20\%), four eyes in group B (17\%), and seven eyes in group C (32\%) demonstrated visual field progression during the 24-month follow-up period.

Regarding intraoperative complications, two cases of conjunctival button hole (one in group A and one in group C) and three cases of mild anterior chamber bleeding (one in each group) were reported. All these complications resolved with no further problems.

Of the total trial patients (71 eyes), 16 (22.5\%) had developed significant cataract late $(5,6,5$ eyes in groups
A, B, and C, respectively), with a moderate to severe drop in BCVA. They were properly managed with an uneventful phacoemulsification procedure through clear corneal incisions.

Mild conjunctival hyperemia and mild anterior chamber flare were detected in all patients within the first postoperative week. Hypotony (IOP $<6 \mathrm{mmHg}$ ) with a shallow anterior chamber was developed in two patients in group A, four patients in group $\mathrm{B}$, and one patient in group $\mathrm{C}$ that resolved spontaneously. No hypotony maculopathy was detected in these eyes. The patients did not report significant postoperative symptoms such as pain or visual loss. No significant

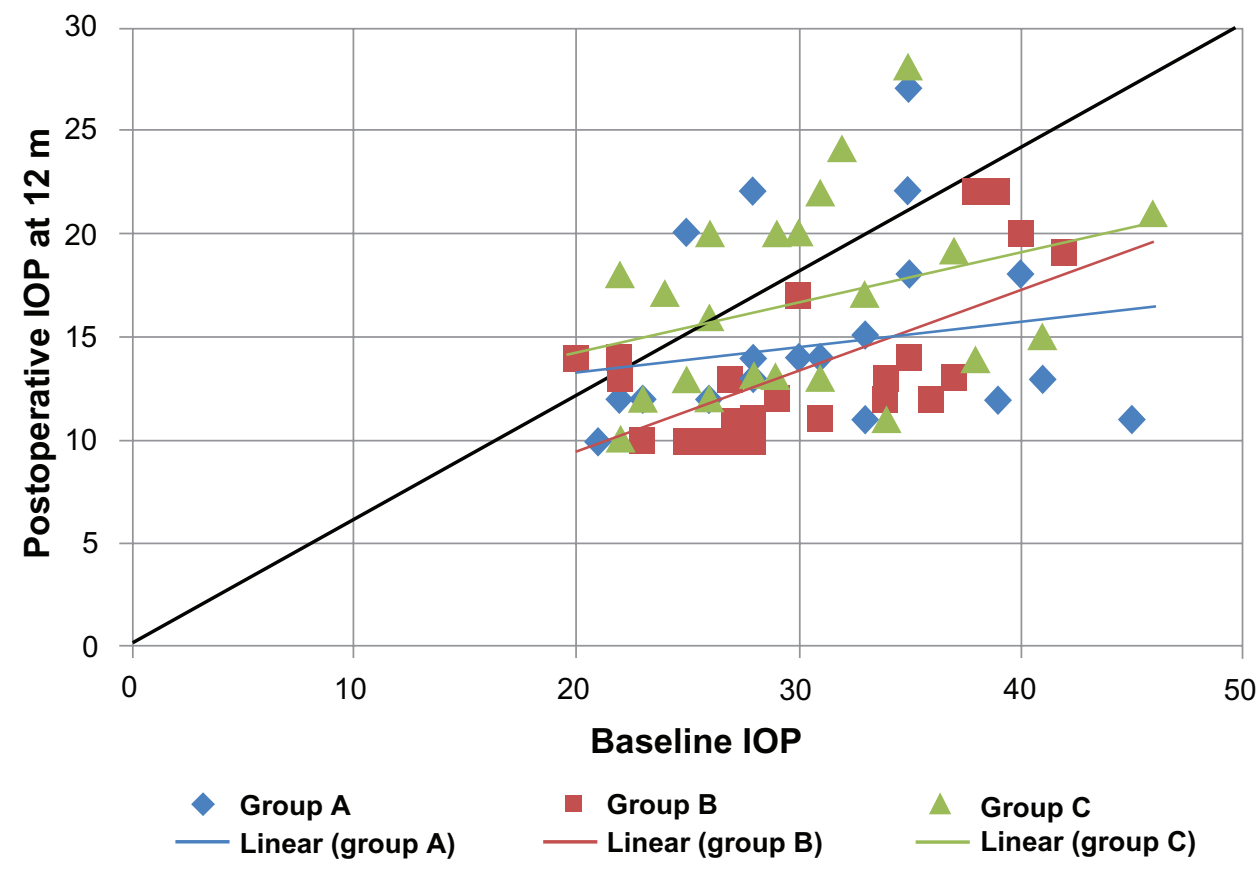

Figure 3 Shows a scatter plot illustrating the proportions of study subjects who meet the criteria for success at 12 months postoperatively. Abbreviation: IOP, intraocular pressure. 


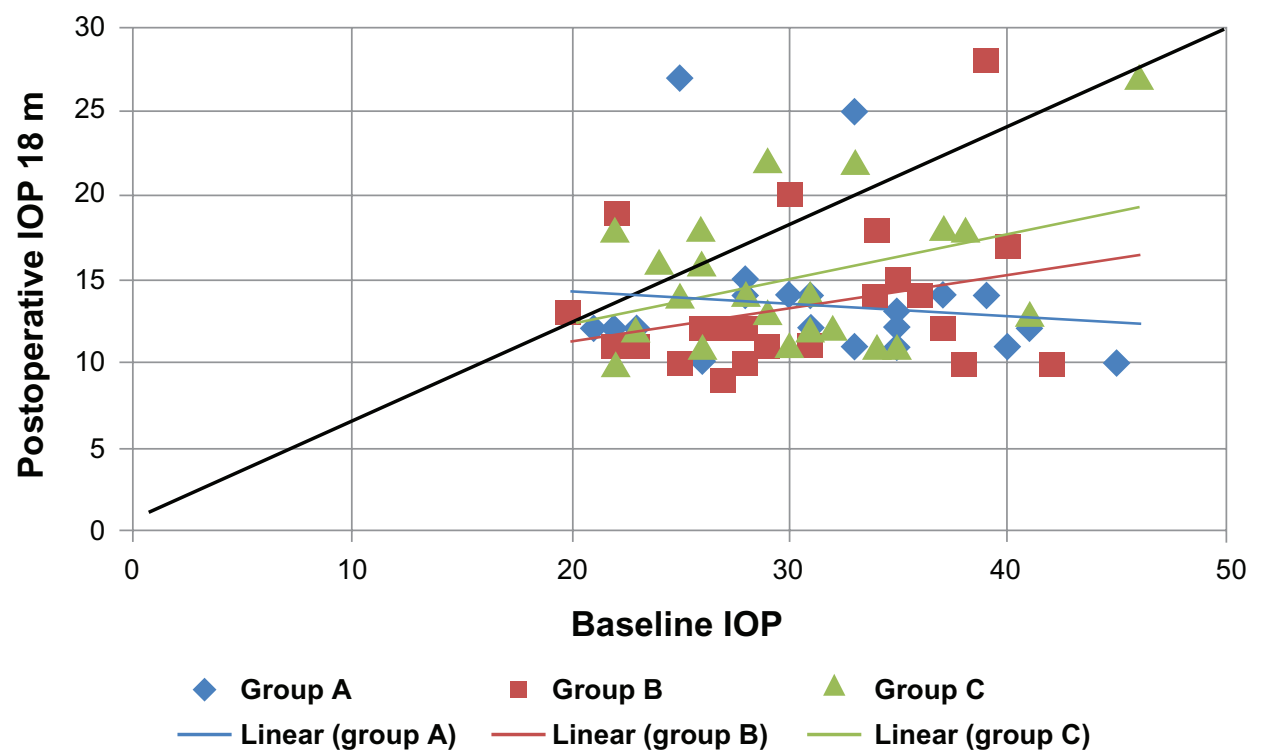

Figure 4 Shows a scatter plot illustrating the proportions of study subjects who meet the criteria for success at 18 months postoperatively. Abbreviation: IOP, intraocular pressure.

complications (such as bleb leakage, long lasting hypotony, hypotony maculopathy, disc swelling, choroidal detachment, blebitis, uveitis, phthisis, or endophthalmitis) were seen in any of the eyes included in the study.

No complications (such as tissue damage of the conjunctiva, the cornea, bleb inflammation or inflammation of its surrounding tissue) were observed after the application of BCECF-AM to group A. Avascularity of the filtering bleb was observed in four cases in group B and not seen in other groups.

\section{Discussion}

Trabeculectomy is the relatively safe and simple single intervention and may be the most efficacious and cost effective long-term solution. In Egypt, it is usually the initial filtration surgery performed on glaucoma patients. Considering that scarring at the surgical site is the most common cause of failure of a trabeculectomy, the high failure rate in primary cases may be explained in part by the fibrotic conjunctival changes induced by trachoma or by the long duration of medical therapy. ${ }^{22}$ Until today, no sufficient method has been established to achieve

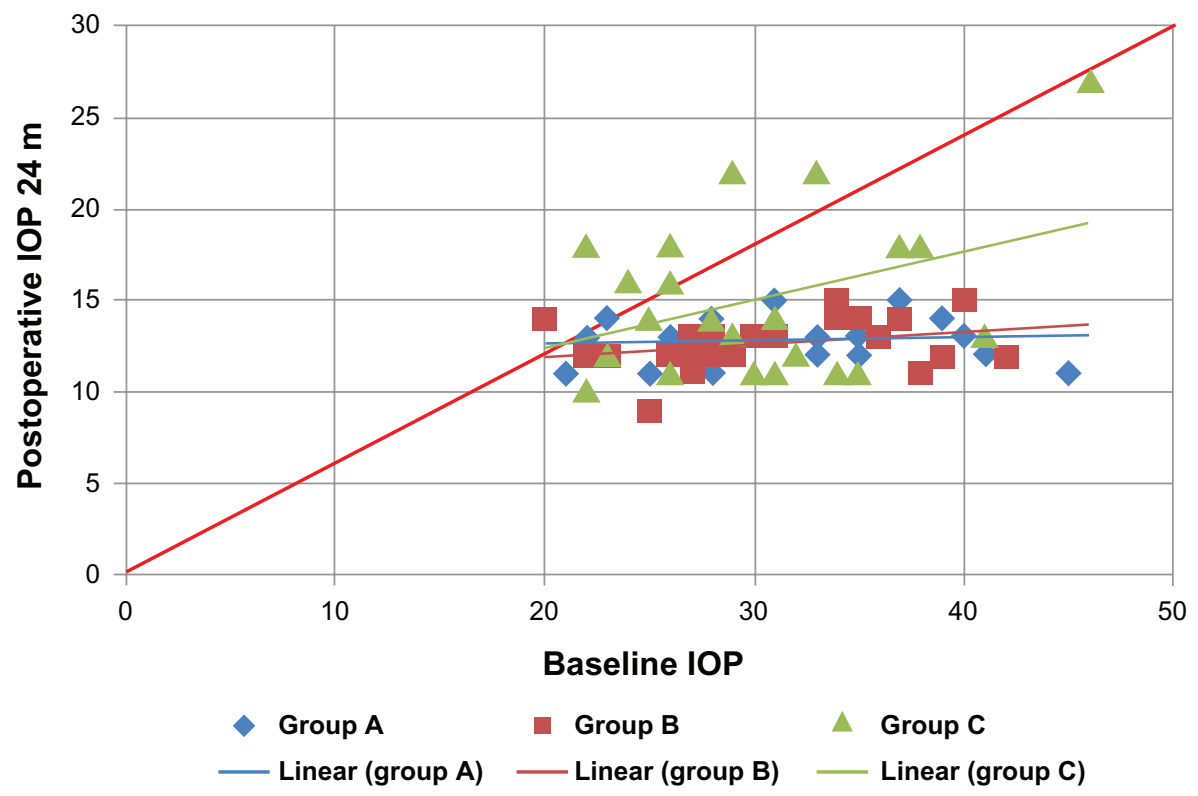

Figure 5 Shows a scatter plot illustrating the proportions of study subjects who meet the criteria for success at 24 months postoperatively. Notes: $\chi^{2}=10.7 ; P=0.22$.

Abbreviation: IOP, intraocular pressure. 
Table 6 Pearson's correlation coefficient between baseline intraocular pressure (IOP) and postoperative IOPs

\begin{tabular}{|c|c|c|c|c|c|c|}
\hline \multirow[t]{2}{*}{ Baseline IOP with } & \multicolumn{2}{|c|}{ Group A } & \multicolumn{2}{|c|}{ Group B } & \multicolumn{2}{|c|}{ Group C } \\
\hline & $\mathbf{r}$ & $P$ & $\mathbf{r}$ & $P$ & $r$ & $P$ \\
\hline Postoperative IOP 12 months & 0.186 & 0.37 & 0.642 & $0.00 I^{*}$ & 0.331 & 0.13 \\
\hline Postoperative IOP I8 months & -0.115 & 0.56 & 0.286 & 0.18 & 0.381 & 0.08 \\
\hline Postoperative IOP 24 months & 0.089 & 0.67 & 0.318 & 0.13 & 0.376 & 0.084 \\
\hline
\end{tabular}

satisfying postoperative long-term surgical results with only minimal or no side effects for the patient.

Despite the positive long-term effects of MMC and 5-FU on prolonged filtration, the application of such cytotoxic drugs to a surgically opened eye increases the incidence of iatrogenic complications, especially for MMC as it diffuses easily into the eye, including thin and avascular filtering blebs, long lasting hypotony due to over filtration and ciliary body toxicity, hypotony maculopathy with prolonged visual impairment, local inflammation, and even endophthalmitis. $5,23,24$ The cytotoxic side effects of 5-FU mainly affect the corneal epithelium, and its clinical use is also limited by the fact that it must be applied repeatedly and it causes pain and discomfort for the patient.

The photoablative potential of BCECF-AM has been described previously ${ }^{15}$ and was confirmed for human Tenon fibroblasts in vitro. ${ }^{16}$

From the results of the current study, trabeculectomy alone had a marked ability to lower IOP; however, when combined with either photodynamic therapy (BCECF-AM) or with an antimetabolite (MMC), the results improved significantly. MMC could be considered a more potent and durable adjunctive to trabeculectomy than BCECF-AM in promoting a reduction in IOP.

The results of this study concur with the results of other studies that also reported the beneficial role of MMC in conjunction with trabeculectomy when compared with trabeculectomy alone..$^{22,25-28}$

A first clinical pilot study for BCECF-AM was comprised of ten patients with one eye with end stage glaucoma and a poor clinical prognosis and assessed the clinical safety,

Table 7 The number of the patients receiving topical antiglaucoma drugs at 24 months postoperatively in each group

\begin{tabular}{llll}
\hline $\begin{array}{l}\text { Postoperative } \\
\text { antiglaucoma } \\
\text { treatment }\end{array}$ & $\begin{array}{l}\text { Group A } \\
(\mathbf{N}=\mathbf{2 5})\end{array}$ & $\begin{array}{l}\text { Group B } \\
\mathbf{( N = 2 4 )}\end{array}$ & $\begin{array}{l}\text { Group C } \\
(\mathbf{N}=\mathbf{2 2})\end{array}$ \\
\hline Complete failure & $4(16 \%)$ & $2(8.3 \%)$ & $4(18.8 \%)$ \\
No treatment & $14(56 \%)$ & $15(62.5 \%)$ & $9(40.9 \%)$ \\
I drug & $1(4 \%)$ & $2(8.3 \%)$ & 0 \\
2 drugs & $6(24 \%)$ & $5(20.8 \%)$ & $6(27.2 \%)$ \\
3 drugs & 0 & 0 & $3(13.6 \%)$ \\
\hline
\end{tabular}

tolerability, and efficacy of BCECF-AM in controlling postoperative IOP. The study had an $80 \%$ success rate. ${ }^{29} \mathrm{In}$ another clinical study, comprised of 42 consecutive eyes of 36 glaucoma patients, each eye received one subconjunctival injection of $80 \mu \mathrm{g}$ BCECF-AM followed by intraoperative illumination with blue light $(\lambda=450-490 \mathrm{~nm})$ for 8 minutes. The results were broken down as follows: $59.5 \%$ a complete success, $16.7 \%$ a qualified success, and $23,8 \%$ failure. ${ }^{25}$ These results are comparable to the results of group B in the study outlined in this paper $(62.5 \%, 29.2 \%$, and $8.3 \%$, respectively). No similar studies could be found in the literature comparing the effect of combined trabeculectomy with MMC and with BCECF-AM. A thorough Internet search was completed.

In terms of efficacy, the MMC combination group (group B) achieved the highest percentage of complete success and the lowest percentage of failure and complete failure over the follow-up period. Trabeculectomy alone resulted in the highest percentage of failure. Although the difference between the groups was marked, it was not statistically significant $(P>0.05)$. Thus, combining trabeculectomy with adjunctive BCECF-AM or MMC makes the procedure more efficient.

Managing the cases of complete failure showed no additional difficulties or complications whether as a result of revising the original fistula with an MMC application or by creating a new one. All cases reported complete success thereafter.

At the 24-month visit, $62.5 \%$ of the MMC combination group (group B) did not need any postoperative drugs compared to $56 \%$ of the BCECF-AM group (group A) and $41 \%$ of the control group (group C). Only three patients, all in group $\mathrm{C}$, needed three drugs to keep their IOP controlled. Although the difference was marked, it was not statistically significant. Thus, adjunctive BCECF-AM or MMC could help the patients to control their IOP without antiglaucoma drugs.

The results of bleb morphology were markedly affected by MMC and BCECF-AM, but not at a statistically significant level. Results were shifted towards type I and II blebs by MMC more than by BCECF-AM. The controls showed the highest percentage of bleb type III and IV. Thus, trabeculectomy combined with adjunctive therapy could be 


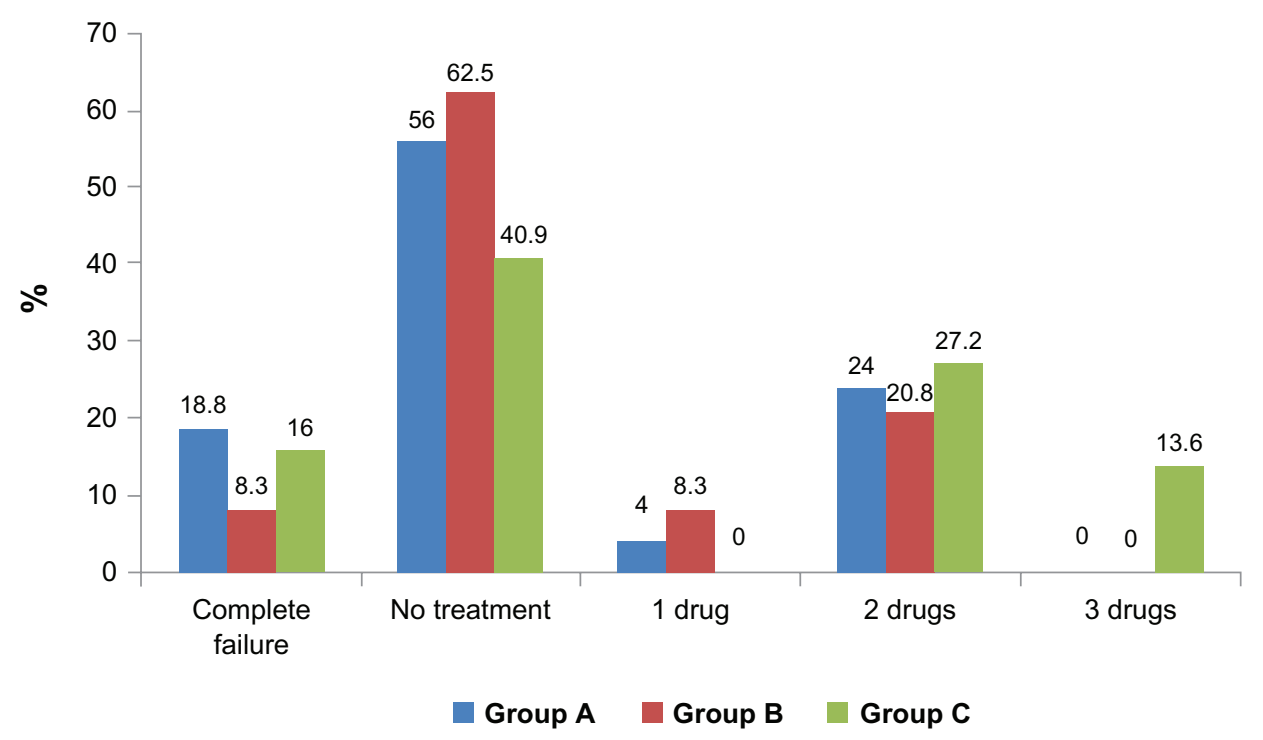

Figure 6 The number of patients in each group receiving topical antiglaucoma drugs at 24 months postoperatively.

considered to decrease the vascular and fibrous content of the bleb. In agreement with El-basty et $\mathrm{al},{ }^{26}$ a correlation between the morphological appearance and the internal structure of the filtering blebs became feasible with the help of UBM.

In the current study, group B had the highest percentage (67\%) showing lower reflectivity compared to group A (40\%) and group C (only 15\%); however, this difference was not statistically significant. A statistical correlation between IOP and the reflectivity within the blebs shows a positive linear relationship. The effect of MMC and BCECF-AM in inhibiting fibroblast migration and collagen synthesis reduces the amount of the fibrous tissue within the bleb and gives more free space for percolation of the aqueous giving the bleb its low reflectivity pattern. A similar study performed by Yamamoto et $\mathrm{al}^{20}$ reported that UBM images of MMC blebs with poor IOP control are characterized by high reflectivity inside the blebs.

Table 8 Bleb reflectivity and morphological subtypes among the studied groups

\begin{tabular}{llllll}
\hline Variable & $\begin{array}{l}\text { Group A } \\
(\mathbf{N = 2 5 )}\end{array}$ & $\begin{array}{l}\text { Group B } \\
(\mathbf{N}=\mathbf{2 4})\end{array}$ & $\begin{array}{l}\text { Group C } \\
(\mathbf{N}=\mathbf{2 2})\end{array}$ & $\chi^{2}$ & $\mathbf{P}$ \\
\cline { 2 - 4 } & $\%$ & $\%$ & $\%$ & & \\
\hline Reflectivity & & & & & \\
High & 20 & 12.5 & 25 & 8.5 & 0.07 \\
Medium & 40 & 20.8 & 50 & & \\
Low & 40 & 66.7 & 15 & & \\
Bleb morphology & & & & \\
Type I & 36 & 45.8 & 18.2 & 7.1 & 0.3 I \\
Type II & 36 & 29.2 & 27.3 & & \\
Type III & 14 & 16.7 & 31.8 & & \\
Type IV & 14 & 8.3 & 22.7 & & \\
\hline
\end{tabular}

The mean bleb height was always markedly larger in group A and B than group $\mathrm{C}$. It was not statistically significant until later in the study, at 24 months, when comparing group B with the control.

The mean bleb breadth was always significantly larger in group A and B than in group C over the follow-up period. When comparing group A to B, it was always larger in group B, but the difference was only statistically significant at 3 and 12 months.

A statistical correlation between the IOP and the height and breadth of the blebs showed an inverse relationship. This could explain the presence of longer blebs of larger breadth in group A and B with higher IOP compared to group C. This was also reported by Yamamoto et $\mathrm{al}^{20}$ and El-basty et $\mathrm{al}^{26}$ when evaluating MMC blebs.

The mean aqueous drainage route was similar in groups $\mathrm{A}$ and $\mathrm{C}$ but less than in group $\mathrm{B}$ at 3 and 12 months postoperatively. However, at 24 months and after, excluding all cases in which drainage routes were poorly visible (six cases in group A, five cases in group B, and seven cases in group C), group A showed the highest mean drainage routes. All differences were not statistically significant.

A statistical correlation between IOP and visibility and measured size of the aqueous drainage route within the blebs showed an inverse relationship, which was also reported by Yamamoto et $\mathrm{al}^{20}$ and Jinza et al..$^{30}$ Thus, BCECF-AM may be considered an effective adjuvant in keeping a relatively large patent drainage route open for a longer time.

As indicated by Wells et al, ${ }^{31}$ UBM can be a useful method to study and explain the mechanisms of filtering structures 
Table 9 The ultrasonic biomicroscopy measurement of the bleb height, breadth, and aqueous drainage route in mm among the studied groups over the follow-up period (at 3, 12, and 24 months)

\begin{tabular}{|c|c|c|c|c|c|c|c|c|}
\hline \multirow[t]{2}{*}{$\begin{array}{l}\text { Postoperative characters } \\
\text { of the bleb at } 3,12,24 \text { months }\end{array}$} & \multicolumn{2}{|c|}{$\begin{array}{l}\text { Group A } \\
(\mathbf{N}=\mathbf{2 5})\end{array}$} & \multicolumn{2}{|c|}{$\begin{array}{l}\text { Group B } \\
(\mathbf{N}=\mathbf{2 4})\end{array}$} & \multicolumn{2}{|c|}{$\begin{array}{l}\text { Group C } \\
(\mathrm{N}=\mathbf{2 2})\end{array}$} & \multirow[t]{2}{*}{ ANOVA } & \multirow[t]{2}{*}{$P$} \\
\hline & Mean & $\pm \mathrm{SD}$ & Mean & $\pm \mathrm{SD}$ & Mean & $\pm \mathrm{SD}$ & & \\
\hline Height at $3 \mathrm{~m}$ & 0.51 & 0.291 & 0.55 & 0.354 & 0.36 & 0.24 & 2.2 & 0.12 \\
\hline Height at $12 \mathrm{~m}$ & 0.51 & 0.291 & 0.55 & 0.354 & 0.36 & 0.24 & 2.2 & 0.12 \\
\hline Height at $24 \mathrm{~m}$ & 0.48 & 0.286 & $0.52 *$ & 0.356 & 0.26 & 0.26 & 4.3 & 0.018 \\
\hline Breadth at $3 \mathrm{~m}$ & $2.22^{*}$ & 0.60 & $2.69 *, \dagger$ & 0.57 & 1.66 & 0.61 & 14.9 & $<0.00$ I \\
\hline Breadth at $12 \mathrm{~m}$ & $2.22^{*}$ & 0.60 & $2.69 *, \dagger$ & 0.57 & 1.66 & 0.61 & 14.9 & $<0.00 \mathrm{I}$ \\
\hline Breadth at $24 \mathrm{~m}$ & $1.99 *$ & 0.89 & $2.32 *$ & 0.97 & 1.15 & 0.92 & 8.4 & 0.001 \\
\hline Route at $3 \mathrm{~m}$ & 0.495 & 0.248 & 0.545 & 0.199 & 0.497 & 0.225 & 0.31 & 0.73 \\
\hline Route at $12 \mathrm{~m}$ & 0.495 & 0.248 & 0.545 & 0.199 & 0.497 & 0.225 & 0.31 & 0.73 \\
\hline Route at $24 \mathrm{~m}^{* *}$ & 0.695 & $1.5 \mathrm{I}$ & 0.40 & 0.306 & 0.314 & 0.285 & 0.97 & 0.38 \\
\hline
\end{tabular}

Notes: *Significant in comparison to the control group; ‘significant in comparison to group A; **six cases of group A, five of group B, and seven of group C were poorly visible at 24 months (these cases were excluded from the calculation at 24 months).

Abbreviation: ANOVA, analysis of variance.

and to evaluate the bleb function. The eyes with good IOP control showed UBM images characterized by better visibility of the route under the scleral flap, low reflectivity inside the bleb, and larger height and breadth.

Visual field testing showed that the PSD changes reached the level of significance only in group $\mathrm{C}$ with $32 \%$ of the eyes demonstrating visual field progression during the 24-month follow-up period. Thus, MMC and BCECF-AM might be considered successful adjuncts to trabeculectomy to retard visual field progression.

The complications reported in this study were mild and insignificant. Hypotony without maculopathy developed more in group B than groups A and C. This was due to excessive filtration, and all eyes affected resolved spontaneously.

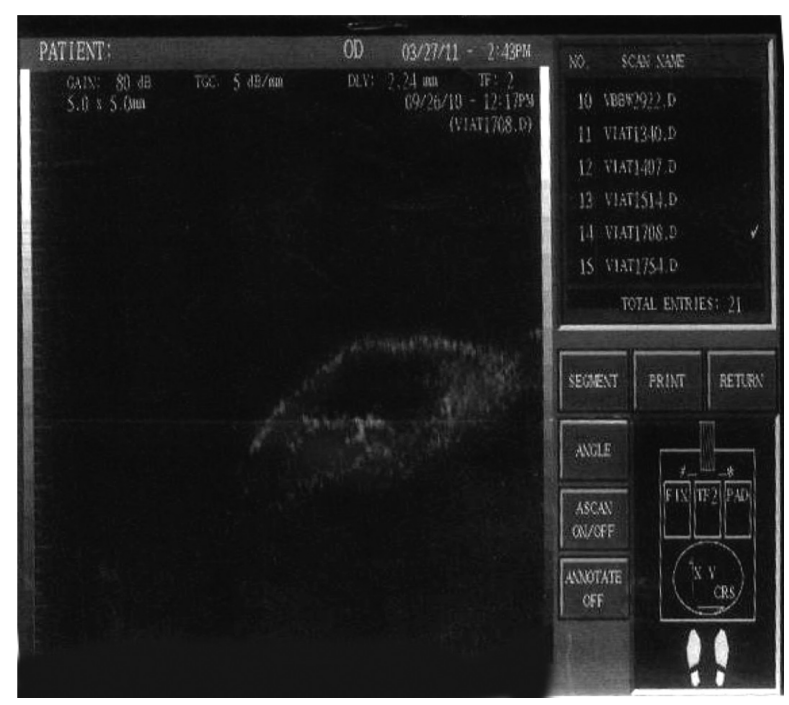

Figure 7 Ultrasonic biomicroscopy image for low reflectivity in a case of the group with mitomycin C (group B).
Avascularity of the filtering bleb was observed in four cases, all in group B (16\%). This was due to MMC effects on the vasculature of the conjunctiva and episclera such as vasoconstriction or endothelial toxicity. ${ }^{22,32}$ These blebs were not complicated by hypotony or infection. The patients did not report such significant postoperative symptoms as pain or visual loss.

Though the carboxyfluorescein applied, as a lipophilic drug, could easily penetrate into adjacent ocular tissues, no conjunctival or corneal-epithelial defect or blebitis was observed in any case in this trial. This damage was avoided by applying the dye subconjunctivally and irradiating the tissue before preparing the artificial fistula. Another way to avoid damage is by localizing its action to the target site by limiting the photoablative effect to the illuminated area.

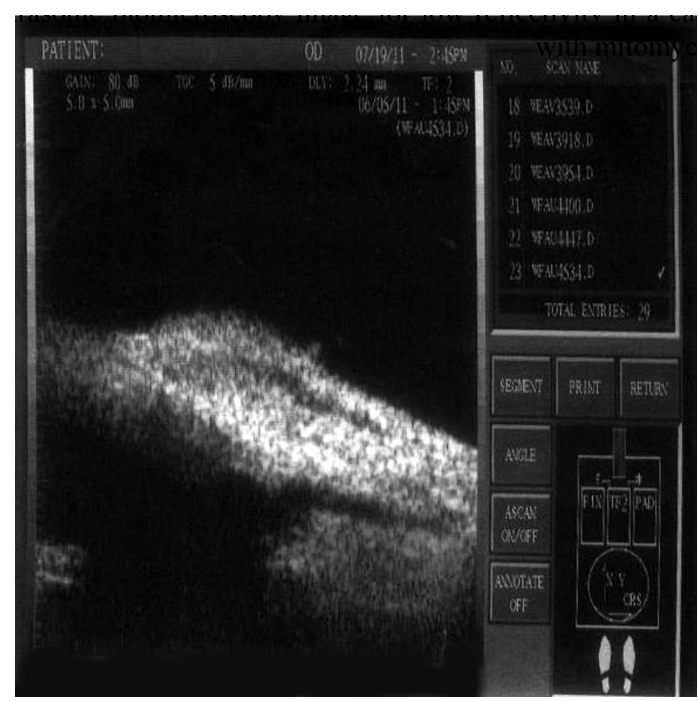

Figure 8 Ultrasonic biomicroscopy image for medium reflectivity in a case of the group with BCECF-AM (group A).

Abbreviation: BCECF-AM, 2',7'-bis-(2-carboxyethyl)-5-(and-6)-carboxyfluorescein, acetoxymethyl ester. 


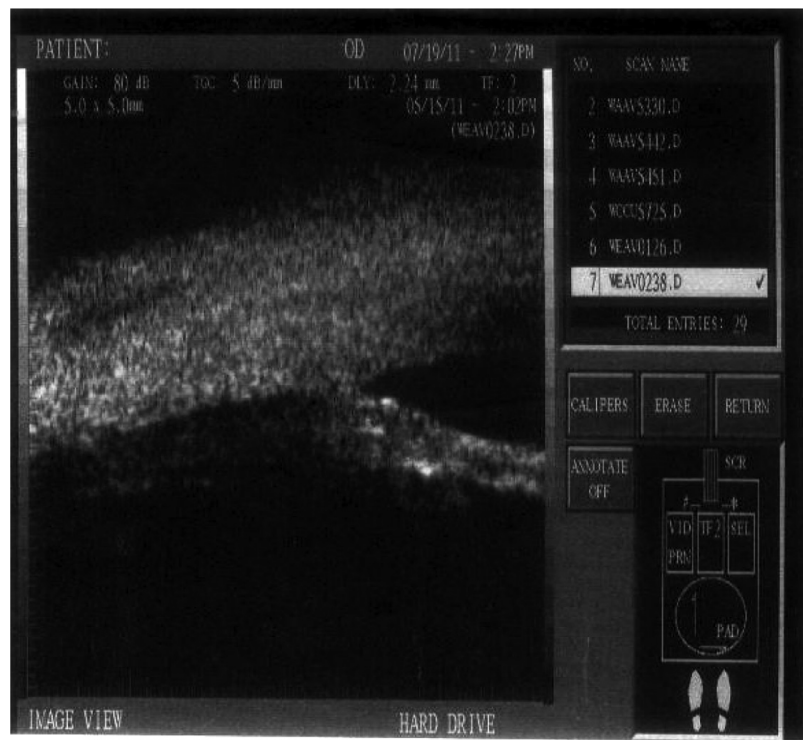

Figure 9 Ultrasonic biomicroscopy image for high reflectivity in a case of the control group (group C).

This was proven in a study in which histological analyses of rabbit eyes treated with carboxyfluorescein was performed. ${ }^{33}$ Ciliary body toxicity could be excluded.

When observing the reported complications of the Fluorouracil (5-FU) Filtering Surgery Study, ${ }^{34}$ such as corneal epithelial toxicity and delayed healing of the conjunctival wound, such significant complications were not encountered with either group in the current study.

The advantages of photodynamic therapy were combined with trabeculectomy in this study. The efficacy of the

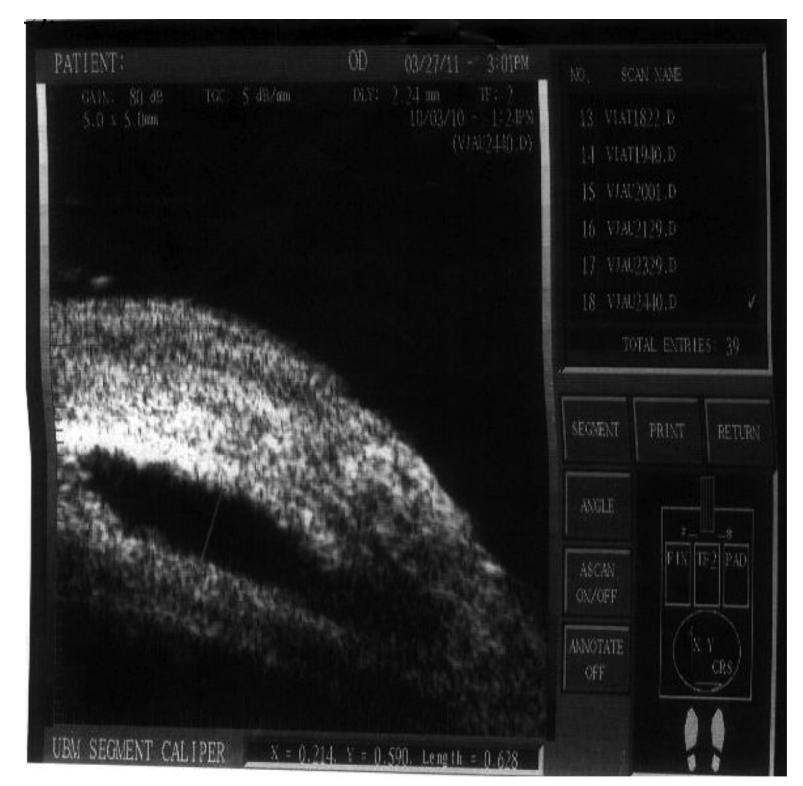

Figure 10 The measurement of the bleb height. Note: Height of the bleb $=0.628 \mathrm{~mm}$.

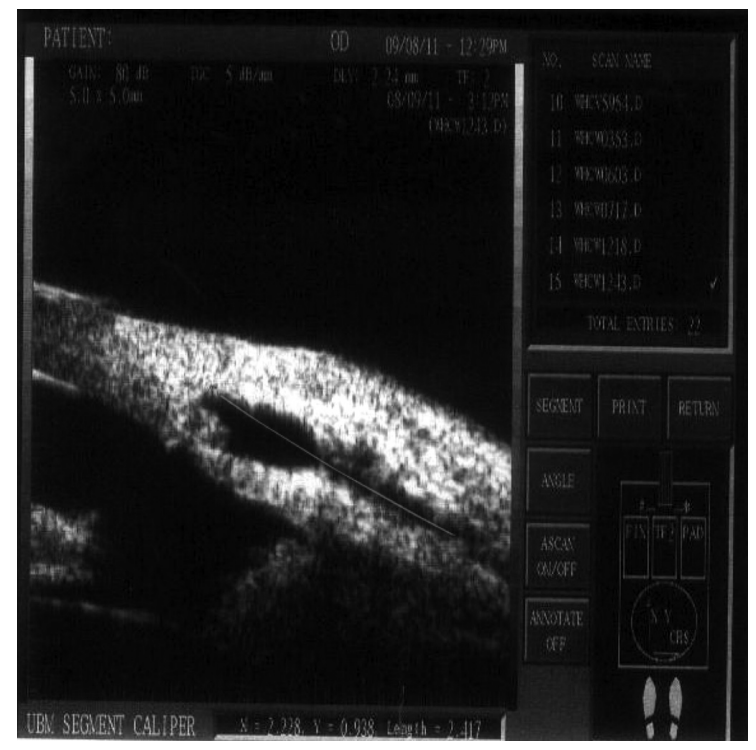

Figure I I The measurement of the bleb breadth. Note: Breadth of the bleb $=2.417 \mathrm{~mm}$.

BCECF-AM-based photodynamic effect was clinically represented by a functioning filtering bleb with a reduced IOP level. The clinical safety and tolerability was represented by the absence of any sign of local toxicity or intraocular inflammation, and a lack of any pain, discomfort, or adverse effects. According to the results of previous studies, and in comparison with this study, it is obvious that complications and side effects related to photodynamic therapy are not significant and less than those reported with MMC, ensuring better clinical safety and tolerability and possibly prolonging bleb survival.

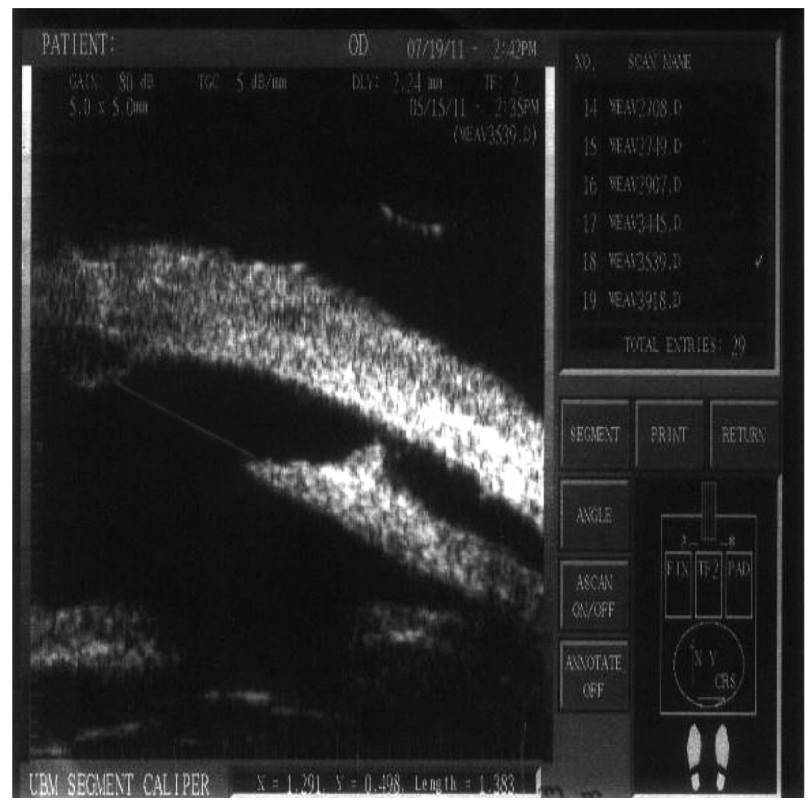

Figure I 2 A visible aqueous drainage route $=1.383 \mathrm{~mm}$. 
Though failure has not yet been investigated any further, the application of MMC in eyes with highly "boosted" scar-forming tissue may still be superior to photodynamic therapy with BCECF-AM. This was also advised by Broadway and Chang. ${ }^{35}$

Parameters such as light dose, irradiation area, time of application and irradiation, total dosage of the dye, and even multiple dosing may be altered in the future to improve the antifibrotic effect of BCECF-AM injection.

\section{Conclusion}

Cellular photoablation using BCECF-AM seems to be a feasible new method when used in combination with glaucoma filtration surgery. It is efficient, tolerable, and relatively safe in managing patients with 1ry OAG. MMC might be considered a more potent and durable adjunctive to trabeculectomy than BCECF-AM in promoting IOP reduction, and also in producing better functioning blebs regarding their morphology. However, photodynamic therapy carries relatively less risk of side effects and complications. Blebs with BCECF-AM and MMC showed UBM images characterized by low reflectivity, larger height and breadth, and better visibility of the route under the scleral flap.

Further studies with larger samples, other types of glaucoma, and longer follow-up periods are needed to assess and evaluate this new adjunctive technique.

\section{Disclosure}

The author reports no conflicts of interest in this work.

\section{References}

1. Khaw PT, Chang L, Wong TT, et al. Modulation of wound healing after glaucoma surgery. Curr Opin Ophthalmol. 2001;12(2):143-148.

2. Loon SC, Chew PTK. A major review of antimetabolites in glaucoma therapy. Ophthalmologica. 1999;213(4):234-245.

3. Costa VP, Wilson RP, Moster MR, et al. Hypotony maculopathy following the use of topical mitomycin C in glaucoma filtration surgery. Ophthalmic Surg. 1993;24(6):389-394.

4. Shields MB, Scroggs MW, Sloop CM, et al. Clinical and histopathologic observations concerning hypotony after trabeculectomy with adjunctive mitomycin C. Am J Ophthalmol. 1993;116(6):673-683.

5. Skuta GL, Beeson CC, Higginbotham EJ, et al. Intraoperative mitomycin versus postoperative 5 -fluorouracil in high risk glaucoma filtering surgery. Ophthalmology. 1992;99(3):438-444.

6. Hill RA, Crean DH, Doiron DR, et al. Photodynamic therapy for antifibrosis in a rabbit model of filtration surgery. Ophthalmic Surg Lasers. 1997;28(7):574-581.

7. Cohan CS, Hadley RD, Kater SB. Zap axotomy: localized fluorescent exitation of single dye-filled neurons induces growth by selective axotomy. Brain Res. 1983;270(1):93-101.

8. Dulon D, Zajic G, Schacht J. Photo-induced irreversible shortening and swelling of isolated cochlear outer hair cells. Int J Radiat Biol. 1989;55(6): 1007-1014.

9. Miller JP, Selverstone AJ. Rapid killing of single neurons by intracellularly injected dye. Science. 1979;206(4419):702-704.
10. Moreno G, Lutz M, Bessie M. Partial cell irradiation by ultraviolet and visible light: conventional and laser sources. Int Rev Exp Pathol. 1969; 7:99-137.

11. Dougherty TJ, Marcus SL. Photodynamic therapy. Eur J Cancer. 1992; 28:1734-1742

12. Weissgold DJ, Hu LK, Gragoudas ES, et al. Photodynamic therapy (PDT) of pigmented choroidal melanoma via a trans-scleral approach [abstract no 58]. Invest Ophthalmol Vis Sci. 1996;37:(S)123.

13. Moshfeghi DM, Peyman GA, Khoobehi B, et al. Photodynamic occlusion of retinal vessels using tin ethyl etiopurin (SnET2): an efficacy study [abstract no 564]. Invest Ophthalmol Vis Sci. 1995; 36:(S)115

14. Cox KW, Shepperd JD, Lattanzio FA, et al. Photodynamic therapy of corneal neovascularization using topical dihematoporphyrin ester [abstract no 2369]. Invest Ophthalmol Vis Sci. 1997;38:(S)512.

15. Dacheux R, Guidry C. Cellular photoablation as a therapy to control proliferative vitreoretinopathy: in vitro studies [abstract no 3476]. Invest Ophthalmol Vis Sci. 1995;36:(S)751.

16. Grisanti S, Gralla A, Maurer P, et al. Cellular photoablation to control postoperative fibrosis in filtration surgery: in vitro studies. Exp Eye Res. 2000;70:145-152.

17. Heuer DK, Barton F, Grehn T, Shaarawy MT, Sherwood MB Consensus on definitions of success. In: Shaarawy TM, Sherwood MB, Grehn F, editors. Guidelines on Design and Reporting of Glaucoma Surgical Trials. Amsterdam: Kugler Publications; 2009: $15-24$.

18. Kronfeld PC. The mechanisms of filtering operations. Trans Pac Coast Otoophthalmol Soc Annu Meet. 1949;33:23-40.

19. Van Buskirk EM. Cysts of Tenon's capsule after filtration surgery. $A m$ J Ophthalmol. 1982;94:522.

20. Yamamoto T, Salcuma T, Kitazawa Y. An ultrasound biomicroscopic study of filtering blebs after Mitomycin C trabeculectomy. Ophthalmology. 1995;102:1770-1776.

21. El-basty, El Din K, Attia E, El-cheweich M. Evaluation of the Filtering Blebs and Aqueous Drainage Route using Ultrasound Biomicroscopy after Trabeculectomy with and without Mitomycin [master's thesis] Cairo, Egypt: Cairo University; 2004.

22. Wilkins M, Indar A, Wormald R. Intraoperative Mitomycin C for glaucoma surgery [Cochrane Review]. Cochrane Database Syst Rev. 2005;4:CD002897.

23. Mietz H. The toxicology of mitomycin C on the ciliary body. Curr Opin Ophthalmol. 1996;7:72-79.

24. DeBry PW, Perkins TW, Heatley G. Incidence of late-onset bleb-related complications following trabeculectomy with mitomycin. Arch Ophthalmol. 2002;120(3):297-300.

25. Kitazawa Y, Kawase K, Matsushita H, Minobe M. Trabeculetomy with mitomycin. A comparative study with fluorouracil.Arch Ophthalmol. 1991; 109(12):1693-1698

26. El-basty M, Elboshy M, Bakir M, Saad A. The use of mitomycin C as an adjunct in glaucoma filtration surgery: experimental and clinical study. Egy Opthalmolgical Soc Bulletin. 1994;87(1):191-198.

27. Shin DH, Kim YY, Sheth N, et al. The role of adjunctive mitomycin C in secondary glaucoma triple procedure as compared to primary glaucoma triple procedure. Ophthalmol. 1998;105:740-745.

28. Chen CW, Huang HT, Bair JS, Lee CC. Trabeculectomy with simultaneous topical application of mitomycin-c in refractory glaucoma. J Ocu Pharmacol. 1990;6(3):175-182.

29. Diestelhorst M, Grisanti S. Photodynamic therapy to control fibrosis in human glaucomatous eyes after trabeculectomy: a clinical pilot study. Arch Ophthalmol. 2002;120:130-134.

30. Jinza K, Saika S, Kin K, Ohnishi Y. Relationship between formation of a filtering bleb and intrascleral aqueous drainage route after trabeculectomy: evaluation using ultrasound biomicroscopy. Ophthalmic Res. 2000;32(5):240-243.

31. Wells AP, Crowston JG, Marks J, et al. A gerypilot study of a system for grading of drainage blebs after glaucoma surgery. $J$ Glaucoma. 2004;13(6):454-460. 
32. Jampel H. Effect of brief exposure to mitomycin $\mathrm{C}$ on viability and proliferation of cultured human Tenon's capsule fibroblastsl. Ophthalmology. 1992;99(9):1471-1476.

33. Grisanti S, Diestelhorst M, Heimann K, et al. Cellular photoablation to control postoperative fibrosis in a rabbit model of filtration surgery. Br J Ophthalmol. 1999;83(12):1353-1359.
34. The Fluorouracil Filtering Surgery Study Group. Three-year follow-up of the Fluorouracil Filtering Surgery Study. Am J Ophthalmol. 1993; 115(1):82-92.

35. Broadway DC, Chang LP. Trabeculectomy, risk factors for failure and the preoperative state of the conjunctiva. J Glaucoma. 2001;10(3): 237-249.

\section{Publish your work in this journal}

Clinical Ophthalmology is an international, peer-reviewed journal covering all subspecialties within ophthalmology. Key topics include: Optometry; Visual science; Pharmacology and drug therapy in eye diseases; Basic Sciences; Primary and Secondary eye care; Patient Safety and Quality of Care Improvements. This journal is indexed on
PubMed Central and CAS, and is the official journal of The Society of Clinical Ophthalmology (SCO). The manuscript management system is completely online and includes a very quick and fair peer-review system, which is all easy to use. Visit http://www.dovepress.com/ testimonials.php to read real quotes from published authors. 